\title{
LEMBAGA PENGAWAS HISBAH DAN \\ RELEVANSINYA PADA DEWAN SYARIAH \\ NASIONAL (DSN) DAN DEWAN PENGAWAS \\ SYARIAH (DPS) DI PERBANKAN SYARIAH \\ INDONESIA
}

\author{
Ririn Noviyanti \\ Dosen Institut Agama Islam (IAI) Al-Qolam, Malang \\ Email: rinoviyanti@gmail.com
}

\section{Abstract}

All economic activity should be run in accordance with the Islamic values is a logical consequence for all Muslims, especially in Indonesia. In the past, in order to ensure economic activities run in eccordance to Islamic values, established oversight agencies (hisbah) at the time of the Prophet Muhammad (PBUH). With the rapid growth of Islamic banking in Indonesia nowadays. Then formed a special institution serves as overseeing the economic activity in the Islamic banks namely the National Sharia Board (DSN) and Sharia Supervisory Board (DPS).This study discusses the suitability DSN and DPS controlling techniques with hisbah controlling techniques during the classical era. Based on the study, can be concluded that: (1) hisbah have significant roles and functions in creating a fair economy (2) DSN and DPS has a role and function as a supervisor in the activities economies Islamic banks in Indonesia. (3) there is a relevance role and function between DPS DSN institutions with technical what was done by hisbah institutions in the classical era.

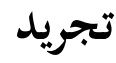

يجب تشغيل كل الأنشطة الاقتصادية وفقا للقيم الإسلامية حيث أها نتيجة

منطقية لجميع المسلمين، وعلى وجه خاص في إندونيسيا. ومن أجل ضمان الأنشطة

الاقتصادية في التشغيل وفقا للقيم الإسامية في الماضي، فأنشأت هيئة الرقابة

(الحسبة) في عهد رسول الله محمد صلى الله عليه وسلم. ومع النمو السريع للعمل 
المصرفي الإسلامي في إندونيسيا حاليا، فيتم إنشاء مؤسسة خاصة تهدف إلى الإشراف على النشاط الاقتصادي في البنوك الإسلامية حيث تسمى بالميئة الشرعية الوطنية (DSN) وهيئة الرقابة الشرعية (DPS). وتبحث هذه الدراسة في ملاعمة DPS و DSN التقليدي. واستنادا إلى هذه الدراسة، يمكن أن نخلص منها فيما يلي: (1) الحسبة لما أدوار ووظائف هامة في إنتاج اقتصاد عادل. (r) إن DSN و DPS لمما دور ووظيفة كمشرف على أنشطة الاقتصاد للبنوك الإسالامية في إندونيسيا. (ب) هناك دور هام ووظيفة هامة بين المؤسسات DSN و مع التقنية التي قامت بها مؤسسات الحسبة في العصر التقليدي.

Keywords: Hisbah, Dewan Syariah Nasional (DSN), Dewan Pengawas Syari'ah (DPS), Bank Syari'ah

\section{A. Pendahuluan}

Universalitas Islam dalam berbagai aspek kehidupan manusia, khususnya dalam ekonomi, menghadirkan sebuah konsekuensi bahwa segala kegiatan perekonomian harus berjalan secara Islami sesuai dengan syariat Islam, baik dalam produksi, konsumsi maupun distribusi. Dengan demikian kesejahteraan dunia dan akhirat (falāh) akan tercapai. ${ }^{1}$

Dalam Islam, pengawasan (Hisbah) kegiatan perekonomian sudah ada sejak zaman Rasūlullāh SAW yang merupakan usaha dalam menyeru terhadap kebaikan, dan meninggalkan keburukan (al-Amru bi al-Ma'rüf wa nahy an almunkar). Hal ini terbukti dalam hadist yang diriwayatkan oleh Abu Hurairah Ra. Yaitu: ${ }^{2}$

1 M. Abdul Mannan, Teori dan Praktek ekonomi Islam, (Yogyakarta: Dana Bhakti Prima Yasa, 1997), hal. 19

2 Imam Tirmiżi, Sunan al-Tirmiżi, (Beirut: Darul Kutub Al-`Ilmiyah), hal. 340 


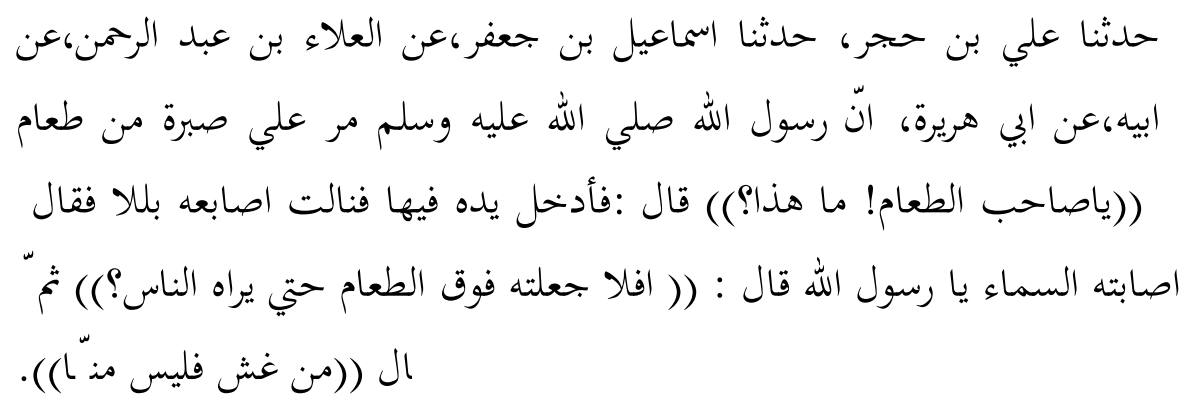

"Bahwa Rasūlullāh Saw. Pada suatu ketika telah berjalan melalui satu bungkusan yang berisikan makanan (di pasar), lalu Rasūlullāh Saw memasukkan tangannya kedalam bungkusan makanan tersebut, kemudian jari Rasülullāh Saw. basah setelah menyentuh makanan tersebut lalu bertanya kepada sang penjual makanan tersebut, "wahai penjual mengapa makanan ini basah?" kemudian penjual tersebut menjawab "Makanan ini terkena hujan". Kemudian Rasūlullāh Saw. Berkata "Kenapa tidak engkau letakkan diatas supaya terlihat oleh orang ramai, seraya berkata "Barang siapa yang menipu, Maka dia bukan dari kalangan kami" (HR. Tirmizii)

Wilāyatul Hisbah merupakan lembaga pengawas yang mempunyai peranan penting dalam perekonomian ummat Islam pada zaman permulaan Islam yang berfungsisebagai pengawasagarberbagai kecurangan dan penyimpangan dalam kegiatan perekonomian tidak terjadi, sehingga keadilan dapat ditegakkan sesuai dengan syari' ah. ${ }^{3}$ Adapun fungsi sebenarnya dari lembaga hisbah mempunyai fungsi yang amat luas meliputi berbagai aspek dalam kehidupan manusia, baik politik, sosial, ekonomi maupun keagamaan. Akan tetapi peneliti membatasi pembahasan hisbah hanya dalam fungsinya di bidang kegiatan perekonomian saja. Adapun fungsi lembaga hisbah dalam kegiatan ekonomi antara lain; (1) memastikan produk yang dipasarkan halal dan sesuai syari'at, (2) mencegah praktik penipuan, penyelewengan dalam kegiatan ekonomi (khususnya dalam barang dan harga), (3) mencegah praktik riba dalam transaksi, (4) mencegah upaya praktik manipulasi harga, (5) mengawal penetapan harga barang. ${ }^{4}$

3 M. Akram Khan, Glossary of Islamic Economics, (London and New York: Mansel, 1990), hal. 57. Lihat juga, M. Umer Chapra, The Future of Economics: An Islamic Perspective, Terj. Amdiar Amir, dkk, (Jakarta: Shari'ah Economics and Banking Institute (SEBI), 2001), hal.78

4 Zulfaqar Bin Mamat, "Institusi Hisbah dan Perananya dalam Mengawal Kegiatan Ekonomi Negara Islam”, Jurnal Muamalat, Vol.III (2010), hal. 113-137 
Pesatnya pertumbuhan ekonomi Islam di Indonesia dengan munculnya bank-bank syari'ah menghadirkan sebuah problem tersendiri. Demi menjamin praktik ekonomi yang Islami, dibentuklah sebuah badan pengawasan terhadap praktek perbankan syariah yaitu Dewan Syariah Nasional (DSN) ${ }^{5}$ dan Dewan Pengawas Syariah (DPS) ${ }^{6}$

Namun, dengan adanya DSN dan DPS tersebut, muncul sebuah pertanyaan sudah sesuaikah teknik pengawasan DSN dan DPS dengan teknik pengawasan hisbah dalam Islam?. Dengan demikian, penelitian ini merupakan penelitian yang sangat urgen untuk dilakukan sehingga peneliti tertarik untuk membahas lebih dalam tentang aplikasi teknik pengawasan hisbah pada DSN dan DPS di perbankan syariah di Indonesia.

\section{B. Tinjauan Umum Tentang Hisbah}

\section{Definisi Hisbah}

Hisbah berasal dari bahasa Arab, berakar kata ' $h a-s a-b a$ ' yang mempunyai makna cukup bervariasi, seperti memperhitungkan, menaksir, mengkalkulasi, memikirkan, opini, pandangan dan lain-lain. Secara harfiyah (etimologis) hisbah berarti melakukan suatu tugas dengan penuh perhitungan. ${ }^{7}$ Ada beberapa kata yang berkaitan dengan hisbah yang berakar dari kata kerja ini, yaitu ihtisāb (computation, calculation, consideration, reflection; debiting; crediting; contentednes,

5 Adalah dewan yang dibentuk oleh Majlis Ulama Indonesia (MUI) dalam rangka efesiensi koordinasi ulama guna menanggapi isu-isu yang berhubungan dengan masalah ekonomi atau keuangan. Di samping itu, DSN diharapkan berfungsi sebagai pendorong terwujudnya penerapan ajaran Islam dalam kehidupan ekonomi. Oleh karena itu, DSN berperan serta secara proaktif dalam menanggapi dan mengantisipasi perkembangan ekonomi dan keuangan syariah. Lihat; Konsideran (bagian b) Surat Keputusan MUI Nomor Kep-98/MUI/III/2001 tentang Susunan Pengurus Dewan Syariah Nasional Masa Bakti 2000-2005

6 DPS adalah dewan yang melakukan pengawasan terhadap prinsip syariah dalam kegiatan usaha bank dan bertanggungjawab dalam memastikan kepatuhan kepada syariah juga berfungsi sebagi pengawas pelaksanaan keputusan DSN di lembaga keuangan syari'ah tersebut. Lihat; Nurul Huda dan Edwin Nasution, Current Issues Lembaga Keuangan Syariah, (Jakarta: Prenada Media Group , 2009) , hal. 58. Muhammad Sayakir Sula, dkk, Asuransi Syariah (Life and General) dan Sistem Operasional, (Jakarta: Gema Asuransi, 2004), hal. 541.

7 Muhammad Djakfar, Hukum Bisnis Membangun Wacana Integrasi Perundangan Nasional Dewan Syariah, (Malang:UIN Press, 2009), hal. 409 
satisfication), dan mu'tasib berarti (bursar, treasurer). ${ }^{8}$

Secara terminologis, menurut Imām Al-Māwardi hisbah adalah menyuruh kepada kebaikan jika terbukti kebaikan ditinggalkan diamalkan, dan melarang dari kemungkaran jika terbukti kemungkaran dikerjakan. ${ }^{9}$ Definisi lain menyebutkan hisbah sebagai fungsi kontrol pemerintahan terhadap tindakan seseorang khususnya dalam ruang lingkup moral, agama dan ekonomi, dan pada area kepentingan bersama atau kehidupan publik pada umumnya, untuk mencapai keadilan dan kebajikan berdasarkan prinsip-prinsip Islam, dan dikembangkan menjadi kebiasaan umum atau adat istiadat yang baik sesuai dengan waktu dan tempat. ${ }^{10}$

\section{Rukun Hisbah}

Lembaga hisbah seperti dijelaskan sebelumnya berfungsi sebagai pelaksana amar ma' rūfnahi munkar. Dengan demikian, terdapat rukun- rukun dalam hisbah antara lain muhtasib, muhtasab alaih, muhtasib fih, nafs al-ihtisab,sebagaimana dijelaskan oleh Imām al-Ghazāli: ${ }^{11}$

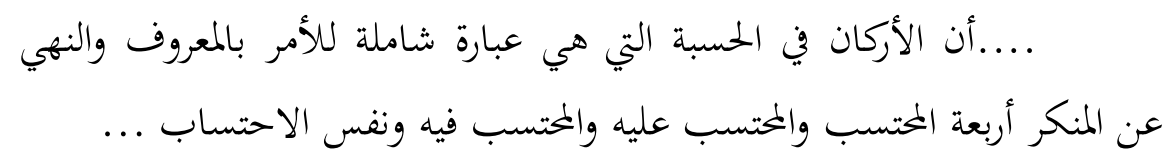

"...bahwa rukun hisbah yang berkaitan dengan pelaksanaan yang ma'rüf dan mencegah yang munkar meliputi empat macam, yaitu, mu'tasib (orang yang mencegah perbuatan munkar), muhtasab alaih (orang yang melakukan kemunkaran), mu'tasib fiih (perbuatan yang dicegah) dan nafs al-I'tisab (cara mencegah kemungkaran)..."

8 Al-Thahir Ahmad al-Zawi dan Muhammad Farid Wajdi, dalam Abdur Rohman, Ekonomi Al-Ghazali; Menelusuri Ekonomi Islam dalam Ihyā' Ulūmuddîn, (Surabaya:Bina Ilmu, 2010), hal. 174

9 Imam Al-Mawardi, Al-Ahkām As-Sulthāniyyah fi al-Wilāyah al-Diniyyah, alih bahasa Fadli Bahri, Cet. 2,Jakarta: Darul Falah hal. 398, lihat juga Ibnu Qayyim al-Jauziyah, atThurūq al-Hukmiyah fi al-Siyāsah al-Syar'iyyah, (Jeddah : Darul Ilmu Fawaid, t.th), hal. 620

${ }_{10}$ Control function of the goverment through persons acting especially in the field of morals, religon and economy, and generally in the areas of collective or public life, to achieve justice and righteousness according to the principles of Islam and commonly known good customs of time and place. Al-Mubarak, dalam Abdul Azim Islahi, Contributions of Muslim Scholars to Economic Thought and Analysis, (Jeddah:King Abdul Aziz,2004), hal. 58

11 Al-Ghazali, Ihyā Ulūmudìn, (Beirut : Dār al-Fikr, 1991),hal. 308 
Berdasarkan definisi tersebut dijelaskan bahwa rukun hisbah ada empat, yaitu:

a. Muhtasib yaitu orang yang menjalankan tugas-tugas hisbah dalam masyarakat dan negara Islam. Ia dilantik resmi oleh pihak imam atau pemerintah untuk memastikan bahwa kebaikan-kebaikan dibuat dan kemungkaran-kemungkaran ditinggalkan. ${ }^{12}$

b. Muhtasib 'Alaih yaitu orang yang melakukan al-munkar atau perilaku yang buruk.

c. Muḥtasib Fîh adalah perbuatan yang dicegah. Adalah segala bentuk kemunkaran yang terlarang untuk dilakukan dan wajib dicegah, baik sudah mukallaf maupun yang tidak (segala usia).

d. Nafs al-Iḥtisāb adalah cara mencegah kemunkaran

\section{Fungsi Hisbah}

Fungsi asal institusi hisbah sangat luas, seluas pengertian amar ma'rüf nahy munkar. Imam Al-Mawardi dalam ulasannya mengenai hisbah menjelaskan hak-hak yang berkaitan dengan fungsi hisbah. Antara lain :13(1) perkara yang berkaitan dengan hak-hak Allah SWT. (2) Perkara yang berkaitan dengan hakhak manusia. (3) Perkara yang berkaitan dengan hak-hak bersama.

Sementara itu menurut Abdul Azim Islahi yang mendasarkan pada kajiankajian kitab klasik, terutama karya Ibnu Taimiyah, menjelaskan fungsi umum al-hisbah, yaitu: ${ }^{14}$

a. Sebuah sistem yang secara umum digambarkan pelaksanaan kebajikan dan kewajiban oleh Muhtasib dan berkaitan dengan aspek agama dan yuridis dalam pengurusannya

b. Digambarkan sebagai praktek dan tehnik pengawasan secara detail. Pengawasan secara prinsip dilakukan atas berbagai bentuk produk

12 Mohd. Parid Sheikh Ahmad \& Mohd. Azmi Omar, al-Hisbah dalam Ekonomi Islam, dalam Sheikh Ghazali Sheikh Abod Zamry Abdul Kadir (Ed.), Pengurusan Perniagaan Islam, (Shah Alam : Hizbi, 1991), hal. 430

13 Imam Al-Mawardi, dalamZulfaqar bin Mamat, "InstitusiHisbah.,hal. 116-117, lihat juga Islahi, dalam M.B. Hendrie Anto, Pengantar Ekonomi Mikro Islami (Yogyakarta : Ekonisis, 2003), hal. 326. Dan, Muhamad, Pengantar Akuntansi Syariah, Edisi 2 (Jakarta : Salemba Empat, 2005), hal. 84-86

14 Islahi, dalam M.B. Hendrie Anto, Pengantar Ekonomi Mikro Islami (Yogyakarta: Ekonisis, 2003), hal. 326. Lihat juga, Muhamad, Pengantar Akuntansi Syariah, Edisi 2 (Jakarta : Salemba Empat, 2005), hal. 84-86 
kerajinan dan perdagangan, bahkan juga mencakup tata administrasi dan kualitas maupun standar produk

Adapun fungsi lembaga hisbah dalam kegiatan ekonomi antara lain;(1) memastikan produk yang dipasarkan halal dan sesuai syari'at, (2) mencegah praktik penipuan, penyelewengan dalam kegiatan ekonomi (khususnya dalam barang dan harga), (3) mencegah praktik riba dalam transaksi, (4) mencegah upaya praktik manipulasi harga, (5) mengawal penetapan harga barang. ${ }^{15}$

\section{Syarat-syarat Muhtasib}

Untuk menjadi mu'tasibdi perlukan beberapa persyaratan yang harus dipenuhi, antara lain: ${ }^{16}$

a. Mu'tasib hendaknya seorang mukallaf, muslim dan sanggup mejalankan tugasnya, tidak disyaratkan bagi anak kecil dan orang kafir

b. Mu'tasib hendaknya beriman, maka orang yang fasiq tidak diperkenankan menjadi $m u^{\prime}$ tasib

c. Mu'tasib hendaknya berlaku adil

d. Mengetahui dan memahami syariat Islam

e. Dapat dipercaya dalam penyampaian kabar berita

Melihat peran dan fungsi yang vital yang terdapat pada hisbah, di Indonesia, untuk menjamin dipraktekkannya sistem syari'ah secara konsisten di lembaga perbankan syari'ah, maka di bentuklah DSN dan DPS sebagai upaya untuk menciptakan suatu pengawasan terhadap praktek dan kegiatan ekonomi.

\section{Teknik Pengawasan Hisbah}

\section{Periode Rasulullah SAW.}

Secara historis, hisbah telah ada semenjak masa Rasūlullāh SAW. ${ }^{17}$ Beliaulah

\footnotetext{
15 Zulfaqar Bin Mamat, “Institusi Hisbah ...”, Jurnal Muamalat, Vol.III (2010), hal. 113-137

16 Al-Ghazali, Ihyā Ulūmudîn..., hal. 118. Lihat juga Ibnu Qoyim, dalam Kamal Fakhry, "Al-Hisbah..., hal. 78

17 Istilah hisbah pada periode Rasūlullāh belum digunakan, dan baru digunakan pada periode kemudian dan tulisan mengenai subyek itu baru muncul lebih akhir lagi. Tulisan paling tua tentang hisbah, termasuk dalam salah satu buku Al-Mawardi dan Abu Ya'la. Kemudian banyak buku yang lebih aktif, bahkan memiliki judul yang sama, seperti AlAhkām al-Sulthaniyah, Al-Ghazali dalam bukunya Ihya' Ulumuddin juga menulis tentang hisbah pada beberapa bagian. Volume yang penuh yang membahas tentang hisbah ditulis
} 
muhtasib pertama dalam Islam. Seringkali beliau masuk kepasar Madinah mengawasi aktivitas jual beli. Sebagaimana dikisahkan Rasulullah Saw. berjalan-jalan di pasar Madinah dan melewati penjual makanan, kemudian beliau memasukkan tangannya kedalam setumpukan gandum dan menemukan bagian gandum yang basah, kemudian Rasulullah SAW bersabda: "Man Ghisna, Falaisa Minna" (Barangsiapa yang menipu saudaranya sendiri, maka bukan bagian dari kita (Ummat Rasululullah Saw). ${ }^{18}$ Dengan demikian dapat disimpulkan bahwa Hisbah pada zaman Rasulullah belum menjadi suatu lembaga, hanya saja praktek - praktek yang mengarah pada kewenangan hisbah dilakukan secara individu yaitu Rasulullah Saw.

\section{Periode Khulafāa' Rāsyidīn}

Pelembagaan hisbah dengan struktur yang lebih sempurna dimulai pada masa Umar bin Khatāb. Ketika itu ia melantik dan menetapkan Wilāyatul hisbah adalah departemen pemerintahanyang resmi. Hisbah pada masa Umar bin Khatāb mempuyai peran penting dalam pengawasan pasar dan kegiatan yang dilakukan didalamnya, yaitu kegiatan ekonomi. Ibnu Saad telah meriwayatkan dari Az Zuhri bahwa Umar bin Khatāb telah mempekerjakan Abdullah bin 'Utbah mengawasi dan memantau pasar. Sebagaimana disebutkan oleh Ibnu 'Abdil Barr bahwa Umar kadangkala mempekerjakan Asyifa' binti Abdullah ar-Qurasyiyah al-Adawiyah untuk mengurus sesuatu tentang urusan pasar. ${ }^{19}$

oleh Abdurrahman Bin Nashri al-Shaizari (wafat 1193), bukunya berjudul Nihāyah al-Rutbah Fi Thalab al-hisbah. Buku ini digunakan sebagai rujukan dasar bagi penulisan soal hisbah di masa berikutnya, misalnya Ma'ālim al-Qurba Fi Ahkām al-hisbah oleh Ibnu Ukhuwwa. Penulis ini juga menggunakan teks al-Shaizari dengan sejumlah tambahan bahkan nama bukunya. Diantara penulis setelah Ibn Taimiyah misalnya Ibnu Jamaah, Ibnu al-Qiyyam, al-Subki dan sebagainya, membahas subyek hisbah dalam tulisannya. Sejumlah buku lainnya tentang hisbah muncul di Andalusia, seperti Adab al-hisbah oleh Muhammad al-Saqti. Dia diangkat menjadi mu'tasib di Andalusia pada akhir abad ke-18. Kemudian Yusuf Bin Abdul Hadi (wafat 1503), menulis buku berjudul al-hisbah. Ibnu Khaldun membahas lembaga hisbah dalam salah satu bagian dari kitab terkenalnya, Muqaddimah. Inilah beberapa nama yang secara cepat bisa disebutkan dalam mencatat literatur tentang hisbah.

18 Muhammad Mahdi Syams ad-Din, Nizhām al-Hukm Wa al-Idārah Fi al-Islām (Beirut: Dar al-Hamra, 1991), hal. 593.

19 Yusuf Qardhawi, Peran Nilai dan Moral dalam Perekonomian Islam, terj. Didin Hafidudin, dkk, (Jakarta : Rabbani Press, 1997), hal. 462 


\section{Periode Dinasti Bani Umayyah}

Daulah Bani Umayyah atau Kekhalifahan Umayyah adalah kekhalifahan Islam pertama setelah masa Khulafāur Rāsyidîn yang memerintah kurang lebih selama 90 tahun dengan Damaskus sebagai pusat pemerintahannya. Nama dinasti ini dirujuk kepada Umayyah bin 'Abd asy-Syams, kakek buyut dari khalifah pertama Bani Umayyah yaitu Muawiyah bin Abu Sufyan. Inilah era dimana kekuasaan menjadi turun temurun hingga akhir kekuasaan pada $750 \mathrm{M}$.

DaulahUmayyah banyak berjasa dalam pembangunan berbagai bidang dalam negara, pada pemerintahan Muawiyah bin AbiSufyan Spesialisasijabatan Qādhi atau hakim dan tentunya Muhtasib. Pada pemerintahan Abdul Malik bin Marwan, dilakukan pembenahan-pembenahan administrasi pemerintahan dan memberlakukan bahasa Arab sebagai bahasa resmi administrasi pemerintahan Islam selain mengubah mata uang Byzantium dan Persia dengan memakai kata-kata dan tulisan Arab pada tahun 659 M. Pada masa inilah, dilakukan penyempurnaan terhadap lembaga hisbah yang disebut sebagai 'diwan' yang berasal dari bahasa persia "diwānah" berarti catatan atau daftar, yang pertama kali didirikan oleh khalifah Umar bin Kha'āb. ${ }^{20}$

\section{Periode Dinasti Bani Abbasiyah}

Pergantian tampuk kekuasaan dari daulah Bani Umayah ke Daulah Abbasiyah tentu mewariskan beberapa aspek yang sangat penting dari perkembangan hisbah itu sendiri, meliputi luasnya wilayah kekuasaan, serta terbentuknya lembaga-lembaga (diwan) oleh penguasa sebelumnya.

Luasnya wilayah kekuasaan Bani Abbasiyah mengakibatkan banyaknya pemasukan terhadap Negara, hal ini menjadikan perlunya pengaturan keuangan Negara sehingga terbentuklah Lembaga-lembaga keuangan negara seperti (a) diwān al-khazanah yang bertugas mengurus perbendaharaan negara, (b) diwān al-azra'u yang bertugas mengurus kekayaan negara yang berupa hasil bumi; dan (c) diwān al-khazāin al-silat yang bertugas untuk mengurus perlengkapan angkatan perang. Hal diatas tentu berakibat terhadap luasnya lingkup tugas serta fungsi lembaga hisbah tersebut dalam kaitanya menyeru kepada kebaikan dan meninggalkan larangan agama.

${ }^{20}$ Imam As-Suyuthi, Tarikh Khulafa', Terj. (Jakarta: Pustaka Al-Kautsar, 2003), hal.253 
Di masa pemerintahan al-Mahdi ( 158-169 H ) wilayah al-hisbah menjadi Institusi yang Independen sebagai suatu lembaga yang menangani persoalan al-amr bi al-ma'rüf wa nahy 'an al munkar khalifah Daulat Abasiyah. Sedangkan Pelembagaan hisbah secara lebih modern dan terstruktur dilakukan pada masa Khalifah al-Mansur dengan menunjuk Yahya ibn Abdullah sebagai mu'tasib pada tahun $507 \mathrm{H}$.

Di sisi lain, perkembangan hisbah di masa Daulah Abbasiyah nampak menonjol dalam bidang ilmiah di banding praktiknya, hal ini tebukti dengan intensnya diskusi mengenai hisbah oleh para Ulama-ulama pada zaman ini, seperti Abu Yusuf, Ibn Taymiyah, Imām Al-Māwardi, Imām Al-Ghazāli, Ibn Khuldun dan lain sebagainya. Karya-karya inilah yang dapat dijadikan pijakan oleh para Ilmuan Muslim untuk mengkaji tentang praktik hisbah dimasa itu. ${ }^{21}$

Hisbah tetap bertahan sepanjang bagian terbesar dari dunia Islam, sampai sekitar awal abad ke-18. Selama periode dinasti Mamluk, institusi seperti itu tampaknya memegang peranan sangat penting, terbukti dari sejumlah hasil yang dicapai selama periode itu. Di mesir, hisbah tetap bertahan sampai masa pemerintahan Muhammad Ali (1805-1849). Di Maroko, lembaga serupa masih ditemukan sampaiawal abad ke-20 ini. ${ }^{22}$ Di Romawi Timuryang telah melakukan kontak dengan dunia Islam melalui perang suci (Perang Salib), lembaga serupa juga di adopsi yang secara jelas dikenal dengan istilah mathessep yang berasal dari istilah muhtasib. ${ }^{23}$

21 Begitu pentingnya peranan hisbah dalam perekonomian tercermin dari banyaknya ulama' yang tertarik untuk membahas perihal hisbah, diantaranya Imām al-Māwardi (w.450/1058), Abu Ya'la (w.458/1065), Imām al-Ghazāli (w.505/1111), Ibn Hazm (w.456/1064), Abdurrahman al-Syayzari (w.589/1193), Ibn Taymiyyah (w.728/1328 ), Ibn al-Ukhuwwa (w.729/1329), al-Nuwayri (w.732/1332), Ibn Khuldun (w.808/1406) dan alMaqrizi (w.846-1442), M. Umer Chapra, The Future of Economics: An Islamic Perspective, hal. 78. Bandingkan: Pusat Pengkajian dan Pengembangan Ekonomi Islam (P3EI), Ekonomi Islam, Jakarta: Raja Grafindo Persada, 2008), hal. 342-343

${ }^{22}$ Nicola Ziadeh,.....hal. 44

23 Ibid., hal.39 


\section{Tinjauan Umum Dewan Syariah Nasional (DSN) dan Dewan Pengawas Syariah (DPS)}

\section{Definisi DSN dan DPS}

Dewan Syariah Nasional Majelis Ulama Indonesia (DSN-MUI), yaitu Dewan yang dibentuk oleh Majelis Ulama Indonesia yang bertugas dan memiliki kewenangan untuk menetapkan fatwa tentang produk, jasa, dan kegiatan bank yang melakukan kegiatan usaha berdasarkan prinsip syariah. DSN merupakan bagian dari MUI. DSN membantu pihak terkait, seperti Departemen Keuangan, Bank Indonesia dan lain-lain dalam menyusun peraturan/ketentuan untuk lembaga keuangan syariah. Anggota DSN terdiri atas para ulama, praktisi dan para pakar dalam bidang yang terkait dengan muamalah syariah. ${ }^{24}$

DSN merupakan bagian dari MUI yang bertugas mengembangkan penerapan nilai-nilai syariah dalam kegiatan perekonomian pada umumnya dan sektor keuangan pada khususnya. Termasuk usaha bank, asuransi dan reksadana. DSN merupakan satu-satunya lembaga yang mempunyai kewenangan untuk mengeluarkan fatwa atas jenis-jenis kegiatan, produk dan jasa keuangan syariah serta mengawasi penerapan fatwa dimaksud oleh lembaga-lembaga keuangan syariah di Indonesia. ${ }^{25}$

DPS merupakan dewan yang melakukan pengawasan terhadap prinsip syariah dalam kegiatan usaha bank. ${ }^{26}$ Pengertian lain menyebutkan, DPS adalah suatu badan yang diberi kewenangan untuk melakukan supervisi/ pengawasan dan melihat secara dekat aktivitas lembaga keuangan syariah agar lembaga tersebut senantiasa mengikuti aturan dan prinsip-prinsip syariah. ${ }^{27}$

Merujuk kepada surat keputusan Dewan Syariah Nasional No. 3 Tahun 2000, bahwa DPS adalah bagian dari Lembaga Keuangan Syariah yang

24 Ahmad Ifham Sholihin, Buku Pintar Ekonomi Syariah, (Jakarta : Gramedia Pustaka Utama, 2010), hal. 241. Lihat juga Asjmuni Abdurrachman, "Prosedur PenetapanProsedur Penetapan Keputusan Fatwa Dewan Syariah Nasional" Al-Mawarid, Edisi XVIII, 2008 hal. 175-176 dan Muhammad Firdaus, dkk. Briefcase Book ...hal. 21

25 Muhammad Firdaus, dkk. Briefcase Book ...hal. 21

${ }^{26}$ Peraturan Bank Indonesia No. 06/24/PBI/2004 Tentang Bank Umum yang Melaksanakan Kegiatan Usaha Berdasarkan Prinsip Syariah

27 The shari'a supervisory board is entrusted with duty of directing, reviewing and supervising the activities of the Islamic financial institution in order to ensure that they are in compliance with Islamic shari'a rules and principles. Lihat Accounting and Auditing Organization For Islamic Financial Institution, 1998, hal. 32 
bersangkutan, yang penempatannya atas persetujuan DSN. DPS adalah suatu badan yang bertugas mengawasi pelaksanaan keputusan DSN di lembaga keuangan syariah. DPS diangkat dan diberhentikan di lembaga keuangan syariah melalui RUPS setelah mendapat rekomendasi dari DSN. ${ }^{28}$

Dari beberapa definisi diatas, penulis mengambil kesimpulan bahwa DPS adalah suatu dewan yang di tunjuk dan di pilih oleh DSN untuk mengawasi praktek kegiatan perbankan syariah agar selalu sesuai dengan prinsip syariah.

\section{Sejarah Terbentuknya DSN dan DPS}

Dewan Syariah Nasional (DSN) dibentuk tahun 1999 oleh Majelis Ulama Indonesia (MUI) Pusat. Tujuan pembentukan dewan itu untuk menangani masalah-masalah yang berhubungan dengan aktivitas Lembaga Keuangan Syariah (LKS) yakni lembaga keuangan yang mengeluarkan produk layanan keuangan syariah, seperti bank syariah, asuransi syariah atau takaful,reksadana syariah dan gadai syariah, yang sebelumnya ditangani langsung oleh Majelis Ulama Indonesia (MUI). ${ }^{29}$

Terbentuk Dewan Syariah Nasional merupakan respon terhadap tinginya gairah mayarakat terhadap Perbankan Islam, sehingga merupakan suatu keharusan akan adanya pengawasan terhadap lembaga keuangan guna terciptanya kepercayaan serta terpenuhinya prosedur yang jelas dalam pelaksanaannya, adapun latar belakang pembentukan DSN adalah :30
a. Untuk mewujudkan aspirasi umat Islam dalam mendorong penerapan ajaran Islam dalam bidang perekonomian keuangan
b. Terciptanya koordinasi dan langkah yang efisien para ulama dalam
menanggapi isu-isu yang terkait dengan masalah ekonomi/keuangan
c. Menanggapi munculnya kasus-kasus di bank syariah sehingga diperoleh kesamaan pandangan dalam menangani masalah-masalah tersebut dengan DPS di masing-masing bank syariah.

${ }^{28}$ Muhammad Firdaus, dkk. Briefcase Book ...hal. 17, Lihat juga Ahmad Ifham Sholihin, Buku Pintar, hal. 240 . Dan Karnaen A. Perwataatmaja dan Muhammad Syafi'i Antonio, Apa dan Bagaimana Bank Islam, Cet. I (Yogyakarta : Dana Bhakti Wakaf, 1992) hal. 2

29 Asjmuni Abdurrachman "Prosedur Penetapan ..., hal. 174
30 Ibid., 


\section{Fungsi dan wewenang DSN - DPS}

Adapun fungsi Dewan Syariah Nasional adalah sebagai berikut : ${ }^{31}$

a. Mengawasi semua produk-produk semua institusi ekonomi dan keuangan syariah di Indonesia.

b. Untuk kesatuan dalam pelaksanaan sistem syariah di setiap institusi keuangan syariah di Indonesia, DSN membuat garis panduan yang dipatuhi oleh semua DPS yang ada pada setiap institusi keuangan syariah untuk mengawasi jalannya sistem syariah di setiap institusi keuangan syariah tersebut

c. DSN juga bertugas meneliti ulang dan memberikan fatwa atas segala bentuk produk yang diusulkan dan dikembangkan oleh institusi

d. Menumbuhkembangkan penerapan nilai-nilai syariah dalam kegiatan perekonomian pada umumnya dan keuangan pada khususnya

Sedangkan wewenang yang dimiliki oleh Dewan Syariah Nasional adalah sebagai berikut;

a. Mengeluarkan fatwa yag mengikat DPS di masing-masing lembaga keuangan syariah dan menjadi dasar tindakan hukum pihak terkait

b. Mengeluarkan fatwa yang menjadi landasan bagi ketentuan/peraturan yang dikeluarkan oleh instansi yang berwenang, seperti Departemen Keuangan dan Bank Indonesia

c. Memberikan rekomendasi dan/atau mencabut rekomendasi nama-nama yang akan duduk sebagai DPS pada suatu lembaga keuangan syariah

d. Mengundang para ahli untuk menjelaskan suatu masalah yang diperlukan dalam pembahasan ekonomi syariah, termasuk otoritas moneter/lembaga keuangan dalam maupun luar negeri

e. Memberikan peringatan kepada lembaga keuangan syariah untuk menghentikan penyimpangan dari fatwa yang telah dikeluarkan oleh DSN

f. Mengususlkan kepada instansi yang berwenang untuk mengambil tindakan apabila peringatan tidak diindahkan.

31 Muhammad Syakir Sula, "Asuransi Syariah", hal. 543-544. Dan Heri Sunanadar, "Peran dan Fungsi.," hal. 163-164. Lihat juga, Khotibul Umam, "Legislasi Fikih Ekonomi Perbankan : Sinkronisasi Peran Dewan Syariah Nasional dan Komite Perbankan syariah", Mimbar Hukum, vol. 24 No. 2 Juni 2012, hal. 361. 
Fungsi DPS pada masing-masing lembaga keuangan syariah adalah sebagai berikut : ${ }^{2}$

a. Melakukan pengawasan secara periodik pada Lembaga Keuangan Syariah (LKS) yang berada dibawah pengawasannya

b. Berkewajiban mengajukan ususl-usul pengembangan LKS kepada pimpinan lembaga yang bersangkutan dan kepada DSN

c. Melaporkan perkembangan produk dan operasional LKS yang diawasinya sekurang-kurangnya 2 (dua) kali dalam 1 (satu) tahun anggaran

d. Merumuskan permasalahan - permasalahan yang memerlukan pembahasan dan solusi dari DSN

\section{Syarat Anggota DSN- DPS}

Anggota DSN terdiridari para ulama, praktisi dan pakar dalam bidang bidang yang terkait dengan syariah dan mu'amalah. Anggota DSN ditunjuk dan diangkat oleh MUI dengan masa bakti selama 5 (lima) tahun. ${ }^{33}$

Persyaratan utama bagi anggota Dewan Pengawas Syariah adalah mereka harus memiliki kemampuan di bidang Hukum Muamalah, Hukum Ekonomi dan Perbankan. Selain itu, anggota DPS juga wajib memenuhi persyaratan berikut, $^{34}$

a. Integritas, anggota DPS yang memenuhi persyaratan integritas tersebut, antara lain adalah pihak-pihak yang; memiliki akhlak dan moral baik, memiliki komitmen untuk mematuhi peraturan perundang-undangan yang berlaku., memiliki komitmen yang tinggi dalam mengembangkan perbankan syariah yang sehat., tidak termasuk daftar tidak lulus sesuai dengan ketentuan yang ditetapkan oleh Bank Indonesia.

b. Kompetensi, anggota DPS yang memenuhi persyaratan kompetensi merupakan pihak-pihak yang memiliki pengetahuan dan pengalaman di bidang syariah muamalah dan pengetahuan di bidang perbankan serta pengetahuan di bidang keuangan secara umum.

32 Keputusan Dewan Pimpinan Majelis Ulama Indonesia Tentang Susunan Pengurus DSN-MUI Nomor. Kep-98/MUI/III/2001. Lihat juga, Ahmad Ifham Sholihin, Buku Pintar, hal. 240,

33 Muhammad Syakir Sula, Asuransi Syariah...,hal. 543

34 Ibid. 
c. Reputasi keuangan, Anggota DPS yang memenuhi persyaratan reputasi keuangan adalah pihak-pihak yang tidak termasuk dalam kredit/ pembiayaan macet, tidak pernah dinyatakan failed atau menjadi direksi atau komisaris yang dinyatakan bersalah menyebabkan suatu perseroan dinyatakan failed dalam waktu 5 tahun sebelum dicalonkan

\section{Teknik Pengawasan DSN- DPS}

Tugas utama DSN-MUI adalah menggali dan merumuskan nilai-nilai syariah dalam bentuk fatwa untuk dijadikan pedoman dalam kegiatan transaksi di lembaga keuangan syariah. DSN-MUI juga mempunyai tugas mengawasi pelaksanaan dan implementasi fatwa-fatwa tersebut di Lembaga Keuangan Syariah (LKS) Melalui Dewan Pengawasan Syariah (DPS) yang merupakan kepanjangan tangan DSN-MUI di lembaga keuangan syariah. ${ }^{35}$ Selain itu, DSN juga mempunyai tugas sbagai berikut :36(1).Menumbuh kembangakan penerapan nilai-nilai syariah dalam kegiatan perekonomian pada umumnya dan sektor keuangan pada khususnya, termasuk usaha bank, asuransi dan reksadana. (2).Mengeluarkan fatwa atas jenis-jenis kegiatan keuangan. (3).Mengeluarkan fatwa atas produk dan jasa keuangan syariah. (4).Mengawasi penerapan fatwa yang telah dikeluarkan.

Fungsi yang diemban DSN untuk melahirkan fatwa dibidang keuangan merupakan bagian dari gelombang kebangkitan ijtihad yang sangat luar bisa terutama dalam bidang ekonomi, finansial dan perbankan kontempore dan sebagai teknik pengawasan terhadap perbankan syariah atas kepetuhannya terhadap syariah itu sendiri. Tidak saja di negara-negara Arab dan Islam, tetapi juga di seluruh penjuru dunia. ${ }^{37}$

DPS mempunyai tugas yang sangat penting dalam perbankan atau institusi keuangan syariah, yaitu :38(1).Membuat persetujuan garis panduan operasional produk perbankan syariah tersebut sesuai dengan ketentuan yang telah disusun oleh DSN. (2).Membuat pernyataan secara berkala pada setiap tahun tentang bank syariah yang berada dalam pengawasannya bahwa bank yang diawasinya telah berjalan sesuai

\footnotetext{
35 Asjmuni Abdurrachman, "Prosedur Penetapan..."., hal. 176

36 Ahmad Ifham Sholihin, Buku Pintar ..., hal. 241

37 Muhammad Firdaus, dkk. Briefcase Book..., hal.25

38 Heri Sunandar, "Peran dan Fungsi.,", hal. 161-162
} 
dengan ketentuan syariah. Dalam laporan tahunan (annual report) institusi syariah, maka laporan dari DPS mesti dibuat secara jelas. (3).DPS wajib membuat laporan tentang perkembangan dan aplikasi sistem keuangan syariah (Islam) di institusi keuangan syariah khususnya bank syariah yang berada dalam pengawasannya, sekurang-kurangnya enam bulan sekali. ${ }^{39}$ Laporan tersebut diberikan kepada Bank Indonesia yang berada di Ibu kota provinsi dan atau Bank Indonesia di Ibukota negara Indonesia di Jakarta.

\section{Mekanisme Kerja DSN - DPS}

Mekanisme kerja DSN dapat digambarkan sebagai berikut. ${ }^{40}$

(3)

(4)

Pengajuan

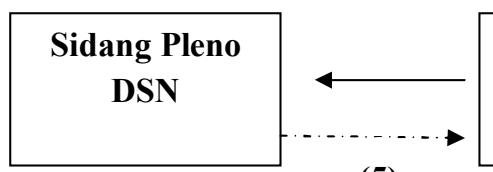

(5)

Jawaban

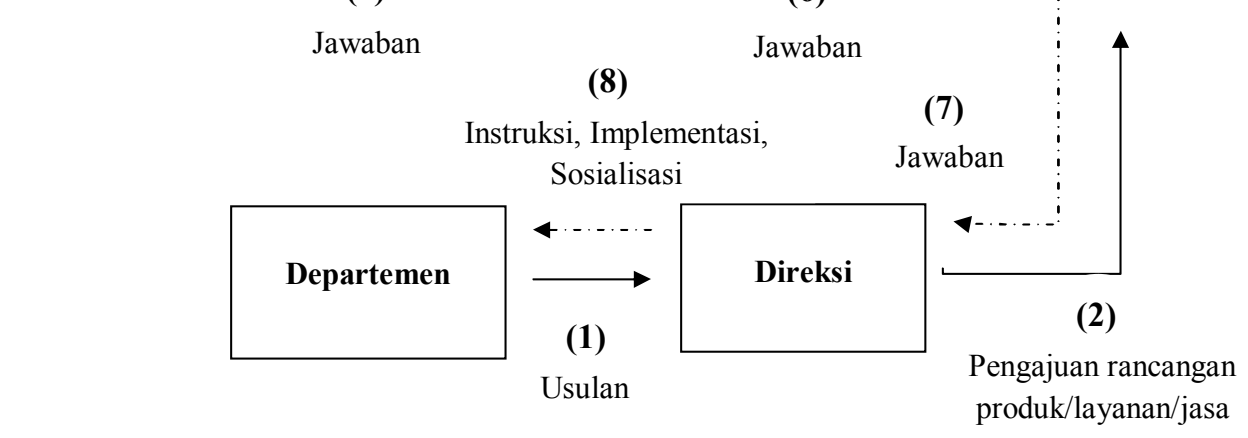

(7)

Pengajuan, setelah rapat dengan direksi dan dept. terkait

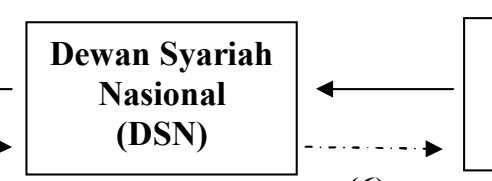

(6)

39 Surat Edaran Bank Indonesia kepada Bank-Bank Syariah di Indonesia pada bulan Februari 2005

40 Muhammad Syafi'i Antonio, Bank Syariah: Dari Teori ke Praktek, (Jakarta : Gema Insani, 2009), hal. 33 
Adapun mekanisme kerja DPS dapat digambarkan sebagai berikut : ${ }^{41}$

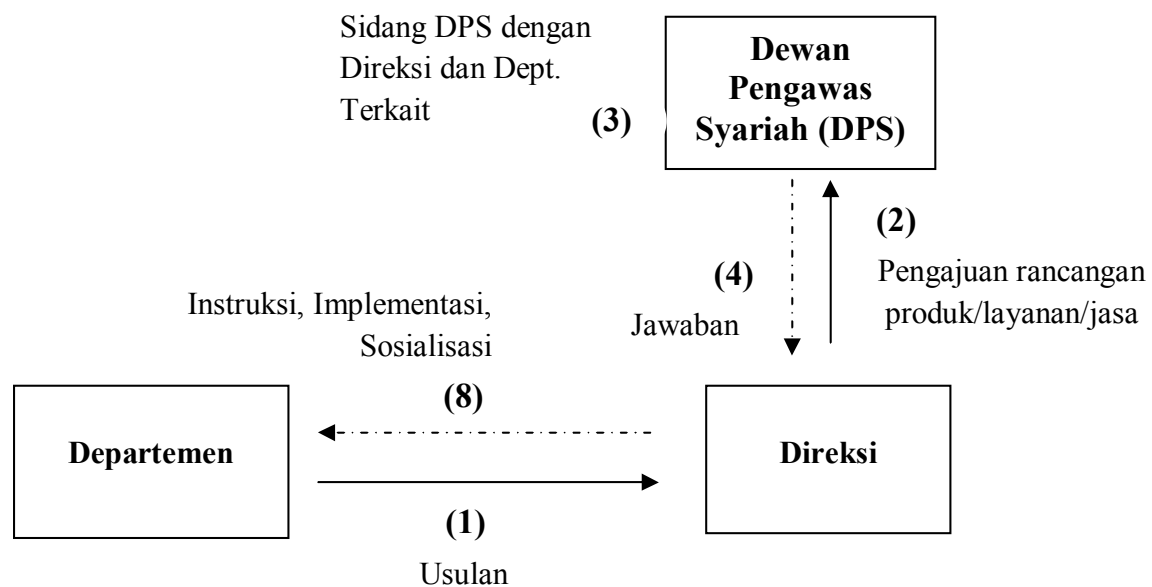

\section{Relevansi Teknik Pengawasan Hisbah dengan DSN - DPS}

Relevansi teknik pengawasan hisbah terhadap lembaga DSN-DPS ditinjau dari fungsi adalah bahwa DSN-DPS mempunyai tugas untuk mempublikasikan penerapan ekonomi Islam melalui fatwa-fatwanya sebagai pedoman pelaksanaan bagi para pelaku ekonomi Islam serta sebagai institusi yang mengawasi jalannya suatu kegiatan perekonomian agar sesuai dengan syari'at. Sebagaimana fungsi pengawasan hisbah di zaman kekhalifahan, sebagai pengawas dalam dilaksanakannya perkara yang $m a^{\prime} r \bar{u} f$ dan ditinggalkannya perkara yang munkar dalam setiap aspek kehidupan umat. Namun, terdapat perbedaan fungsi dalam hisbah dan DSN-DPS yaitu fungsi dalam ruang lingkup pengawasan, hisbah mempunyai ruang lingkup pengawasan yang lebih luas dan global karena hisbah berfungsi sebagai pengawas terhadap seluruh kegiatan muamalah yang menyangkut hak-hak terhadap Allah, manusia dan hak bersama. Sedangkan DSN-DPS mempunyai fungsi yang lebih terfokuskan kepada pengawasan kegiatan muamalah dalam perekonomian agar tidak menyimpang dari syari'ah.

\footnotetext{
41 Ibid., hal. 31
} 
Relevansi hisbah terhadap lembaga DSN-DPS ditinjau dari syarat-syarat keanggotaan adalah muhtasib sebagai orang yang diangkat oleh penguasa atau wakilnya untuk memonitor urusan rakyat, melihat kondisi mereka dan melindung kemaslahatannya yang mengetahui dan memahami syariah serta berkomitmen menerapkannya dalam berbagai kegiatan masyarakat untuk mencapai kesejahteraan. Sebagaimana syarat DSN-DPS, bahwa DSN-DPS beranggotakan para ulama, praktisi dan pakar dalam bidang-bidang yang terkait dengan syariah dan muamalah. Mempunyai moral dan akhlaq yang baik, memiliki komitmen untuk mengembangkan perbankan syariah untuk kesejahteraan ummat. Dewan Pengawas Syariah terdiri dari orang-orang yang kompeten, yag menguasai ilmu perbankan atau keuangan secara umum untuk mengawasi operasional bank serta menguasai ilmu syariah khususnya tentang transaksi ekonomi syariah (muamalat) untuk mengawasi aspek syariah terhadap produk bank, selain itu juga mereka dituntut untuuk mengkonsentrasikan kesempatan dan pemikiran hanya untuk pengabdian kepada bank tempat mereka bekerja.

Relevansi hisbah terhadap lembaga DSN-DPS ditinjau dari tugasnya adalah tugas hisbah dalam memantau penegakkan keadilan di masyarakat dan mengintervensi setiap kali jalannya roda ekonomi dipermainkan oleh perorangan atau kelompok.Hal ini serupa dengan DSN-DPS bertugas untuk menggali dan merumuskan nilai-nilai syariah dalam bentuk fatwa untuk dijadikan pedoman dalam kegiatan transaksi di lembaga keuangan syariah, membantu sosialisasi perbankan atau institusi keuangan syariah kepada masyarakat dan memberikan masukan (input) bagi pengembangan dan kemajuan institusi keuangan syariah.

\section{E. Penutup}

Berdasar pada uraian di atas, DSN-DPS merupakan "reinkarnasi" -tidak sempurna- dari institusi hisbah. Namun dalam penerapan praktek pengawasannya terhadap lembaga keuangan syariah atau perbankan syariah, banyak mengacu pada konsep hisbah dalam Islam.

Tujuan dari hisbah dan DSN-DPS mempunyai kesamaan yaitu menyuruh kepada yang ma' ruf dan mencegah kepada yang munkar, tapi diantara keduanya memiliki ruang lingkup pengawasan yang berbeda. Hisbah mempunyai ruang 
lingkup pengawasan secara keseluruhan dalam berbagai aspek kehidupan, sedangkan DSN-DPS terbatas pada pengawasan dalam aspek ekonomi perbankan.

Dalam upayanya menjalankan tugas dan fungsinya, DSN-DPS tidak luput dari berbagai kritik dan evaluasi dari berbagai kalangan, terutama dari lapisan praktisi perbankan, akademisi dan ulama'. Antara lain, DSN-DPS bertugas mengawasi dan bermitra dengan lembaga keuangan syariah yang notabene diurus oleh praktisi-praktisi yang profesional. Oleh karena itu, mitra kerjanya pun harus menyeimbangi secara profesional. Namun, di lapangan masih banyak didapatkan anggota DSN-DPS yang memahami tentang hokum syariah tapi kurang professional dalam urusan perbankan. Oleh karenaitu, Badan Pelaksana Harian DSN perlu dipimpin oleh seorang excecutive director yang diambil dari kalangan profesional, digaji yang layak, dan benar-benar bekerja secara full time untuk DSN dengan manajemen modern.

Diharapkan, DSN bukan hanya sebagai institusi pembuat fatwa di bidang ekonomi syariah, tetapi juga diharapkan sebagai lembaga riset, yang dapat memberikan kontribusi konsep-konsep baru ekonomi syariah. Oleh karenanya, rekrutmen terhadap pakar-pakar syariah dan praktisi yang mumpuni, mempunyai visi keumatan yang jelas menjadi sangat penting. Ulama-ulama yang faqih dan saleh benar-benar diharapkan dapat berperan aktif di DSNDPS. Tidak hanya itu DSN-DPS juga perlu membangun integritasnya agar berwibawa di hadapan umat, bukan sebagai corong yang dimanfaatkan atau memanfaatkan pemerintah. Tetapi sebagai institusi yang berfungsi mengawasi dan mengembangkan ekonomi syariah.

\section{DAFTAR PUSTAKA}

Abdurrachman, Asjmuni. 2008. "Prosedur PenetapanKeputusan Fatwa Dewan Syariah Nasional" Al-Mawarid, Edisi XVIII

Anto, M.B. Hendrie. 2003. Pengantar Ekonomi Mikro Islami, Yogyakarta: Ekonisis

Antonio, Muhammad Syafi'i. 2009. Bank Syariah: Dari Teori ke Praktek, Jakarta: Gema Insani

Chapra, Umer. 2001. The Future of Economics: An Islamic Perspective, Terj. Amdiar Amir, dkk, Jakarta: Shari'ah Economics and Banking Institute (SEBI) 
Djakfar, Muhammad. 2009. Hukum Bisnis Membangun Wacana Integrasi Perundangan Nasional Dewan Syariah, Malang: UIN Press

Huda, Nurul.dan Nasution, Edwin. 2009. Current Issues Lembaga Keuangan Syariah, Jakarta: Prenada Media Group

Islahi, Abdul Azim. 2004. Contributions of Muslim Scholars to Economic Thought and Analysis, Jeddah:King Abdul Aziz

Keputusan Dewan Pimpinan Majelis Ulama Indonesia Tentang Susuna Pengurus DSN-MUI Nomor. Kep-98/MUI/III/2001.

Khan, M. Akram. 1990. Glossary of Islamic Economics, London and New York: Mansel

Konsideran (bagian b) Surat Keputusan MUI Nomor Kep-98/MUI/III/2001 tentang Susunan Pengurus Dewan Syariah Nasional Masa Bakti 20002005

Mamat, Zulfaqar Bin. 2010 "Institusi Hisbah dan Perananya dalam Mengawal Kegiatan Ekonomi Negara Islam", Jurnal Muamalat, Vol. III

Mannan, Abdul. 1997. Teori dan Praktek ekonomi Islam,Yogyakarta: Dana Bhakti Prima Yasa

Muhamad, 2005. Pengantar Akuntansi Syariah, Edisi 2, Jakarta: Salemba Empat Al-Mawardi, Imam. Al-Ahkām As-Sulthāniyyah fi al-Wilāyah al-Diniyyah, Terj. Fadli Bahri, Cet. 2, Jakarta: Darul Falah

Peraturan Bank Indonesia No. 06/24/PBI/2004 Tentang Bank Umum yang Melaksanakan Kegiatan Usaha Berdasarkan Prinsip Syariah

Perwataatmaja, Karnaen A. dan Antonio, Muhammad Syafi'i. 1992. Apa dan Bagaimana Bank Islam, Cet. I , Yogyakarta: Dana Bhakti Wakaf

Pusat Pengkajian dan Pengembangan Ekonomi Islam (P3EI), 2008. Ekonomi Islam, Jakarta: Raja Grafindo Persada

Rohman, Abdur. 2010. Ekonomi Al-Ghazali; Menelusuri Ekonomi Islam dalam Ihyā' Ulūmuddîn, Surabaya: Bina Ilmu

Sholihin,Ahmad Ifham. 2010. Buku Pintar Ekonomi Syariah, Jakarta: Gramedia Pustaka Utama

Surat Edaran Bank Indonesia kepada Bank-Bank Syariah di Indonesia pada bulan Februari 2005

As-Suyuthi, Imam. 2003. Tarikh Khulafa', Terj. Jakarta: Pustaka Al-Kautsar Syakir Sula, Muhammad,dkk, . Asuransi Syariah (Life and General) dan Sistem Operasional, Jakarta : Gema Asuransi. 
Syams ad-Din, Muhammad Mahdi. 1991. Nizhām al-Hukm Wa al-Idārah Fi alIslām, Beirut: Dar al-Hamr.

Tirmiżi, Imam. Sunan al-Tirmiżi, Beirut: Darul Kutub Al-'Ilmiyah

Umam, Khotibul. “Legislasi Fikih Ekonomi Perbankan : Sinkronisasi Peran Dewan Syariah Nasional dan Komite Perbankan syariah", Mimbar Hukum, vol. 24 No. 2 Juni 2012

Qardawi, Yusuf. 1997. Peran Nilai dan Moral dalam Perekonomian Islam, terj. Didin Hafidudin dkk., Jakarta: Rabbani Press

Qayyim al-Jauziyah, Ibnu. at-Thurūq al-Hukmiyah fi al-Siyāsah al-Syar'iyyah, Jeddah: Darul Ilmu Fawaid 